\title{
Editorial
}

\section{Filling the gap between theory and practice}

Jcom's adventure was launched nearly eight years ago, when a group of lecturers and former students of the Master's degree in Science Communication at SISSA of Trieste, decided to have training joined by the commitment to research on science communication issues.

The favourable environment of the Master's degree - for the first time in our country - promoted the awareness that the community of professionals, and not only the one of academics, and sociologists in particular, should find more specific and systematic instruments for analysis to understand the role and the functions of communication in the science-society relation.

The insight and the proposition, both coming from Pietro Greco, found the necessary institutional support at SISSA.

It is important to recall these early steps to describe the changes I will illustrate in this editorial. From September 2009 I will be the new director of this journal. I will replace Pietro. Those who know science communication in Italy, and know that its history is intertwined with the history of the Master's degree at SISSA, will also see this change as a mark of continuity. It is partly true. Both Pietro and me were members of the group that founded Jcom and have been cooperating for many years in many domains. But taking the helm of a journal necessarily means giving also a personal mark.

As I thank Pietro for everything he has done for the journal - and hopefully he will continue to do as an editorialist and a member of the editorial office - it is timely to let Jcom's readers know what my view of the journal is and what differences they will found in the future.

One of the most important problems we have dealt with over the years is the definition of a precise identity. What place is Jcom to take, for example beside Science Communication or Public Understanding of Science (PUS), i.e. the journals most similar to us?

I believe Jcom is not in competition with those two journals and this comparison is not totally proper. Let's see why.

In 2007, Steven Miller, during the annual conference on science communication of the British Association for the Advancement of Science, carried out an exploratory survey to see to what extent the professionals committed in various practical activities turn to the research literature relevant to their interests [1]. The results showed a substantial distance between the two communities: $40 \%$ of the interviewees said they did not read any journal among the most important in the field. In particular, $42 \%$ said they read PUS and 36\% Science Communication. On the other hand, 55\% had never read either of them. The framework outlined, as Miller himself maintained, is probably even optimistic comparing to other international contexts, where the tradition in practical and research activities in science communication is weaker than in the UK.

Apparently, journalists, museum curators, explainers, institutional communicators, event organizers who deal with science, technology and medicine do not think in their professional life it is relevant to read about the research findings of media sociologists, social scholars in the field of science, historians and science philosophers with an interest in communication.

I believe that one of the most important functions of Jcom is to contribute to fill this gap, in other words to reduce the distance between theory and practice. With a better focus than so far, we will try to create an atmosphere in which those who daily deal with communication can find a language meeting their needs and, conversely, those who are committed to either empirical or theoretical research can make an attempt to describe more effectively the deep changes in the science-society relations, which reflect the wider transformations in the relations among democracy, market and knowledge in a globalized world.

Our wider ambition is to contribute to shaping the figure of a "total communicator" of science [2], able to penetrate into the cultural, social, political and economic dimensions of knowledge-based society.

The demand for science communication and science communicators is still too often reduced exclusively to the demand for popularizers, for simplifiers or, at most, for facilitators of a science-society dialogue, according to the new prevailing rhetoric. Needless to say, they are crucial roles and functions I do not intend to diminish or put aside in the name of an alleged needed and progressive alternation of the 
top-down model, the dialogic model and the contextual one. However, I believe that the demand for science communication now embraces an increasingly wider array of functions, which cannot be easily constrained within limited patterns, and it must be met with an equally wider offer.

Total communicators should pay utmost attention to the reflections and the research on science communication if they are to take on a prominent social function in the discussion and in the decisions on the topical issues in the public debate - bioethics, environment, energy - in which science and technology play a priority role.

We need to outline a new political-cultural role of science communication in which theory and practice are to strengthen each other. Our editorial office will work more and more to make Jcom one of the main protagonists in the implementation of this project.

Translated by Massimo Caregnato

Nico Pitrelli

\section{Notes and references}

[1] S. Miller (2008), So Where's the Theory? on the Relationship between Science Communication Practice and Research, in D. Cheng, M. Claessens, T. Gascoigne, J. Metcalfe, B. Schiele and S. Shi (ed.), Communicating Science in Social Contexts. New models, new practices, Springer Verlag, pp. 275-287, available at $\mathrm{http}: / / \mathrm{www}$. springerlink.com/content/k323m1431u13n56u/?p=d9f626f773ff413a8411420485c51a3f\&pi=15.

[2] The definition of this term belongs to Pietro Greco.

How TO CITE: $\quad$ N. Pitrelli, Filling the gap between theory and practice, Jcom 08(03) (2009) E. 